\title{
Reflexões sobre a integração das TIC na Educação Física escolar
}

\section{RESUMO}

Esse ensaio tem o propósito de explicitar os desafios encontrados por professores e instituições educacionais no processo de implementação das TIC em âmbito escolar e na prática pedagógica do professor de Educação Física. Entender como utilizá-las no contexto educacional e ter conhecimento do suporte e dos materiais necessários para seu bom aproveitamento nas aulas é uma tarefa a ser assumida por toda a comunidade escolar. Com apoio na revisão de literatura, constataram-se e colocaram-se em debate as principais dificuldades de integração das TIC no ambiente escolar, assim como a necessidade de formação docente continuada e a importância da efetivação de políticas públicas voltadas para Educação Física escolar

PALAVRAS-CHAVE: Educação física escolar; TIC; Desafios; Formação de professores; Prática pedagógica

\section{Lauriano CecchinWarth}

Mestre em Educação Física Prefeitura Municipal de Florianópolis, Florianópolis, Brasil laurianowarth@gmail.com https://orcid.org/0000-0001-7221-6140

Viviane PreichardtDuek

Doutora em Educação Universidade do Estado de Santa Catarina,

Departamento de Educação Física,

Florianópolis, Brasil

vividuek@hotmail.com https://orcid.org/0000-0002-0774-7495

Geyson Ricardo Zilch Doutorando em Ciência do Movimento Humano Universidade do Estado de Santa Catarina, Departamento de Educação Física,

Florianópolis, Brasil geysonzilch@hotmail.com https://orcid.org/0000-0002-3818-7742

GelcemarOliveria Farias Doutora em Educação Física Universidade do Estado de Santa Catarina, Departamento de Educação Física, Florianópolis, Brasil fariasgel@hotmail.com https://orcid.org/0000-0003-3552-3437 


\title{
Reflectionsontheintegrationof ICT in schoolPhysicalEducation
}

\begin{abstract}
Thisessayaimstoexplainthechallengesfacedbyteachersandeducationalinstitutions theprocessofimplementing ICT in schoolsand in thepedagogicalpracticeofthePhysicalEducationteacher. Understandinghowto use them in theeducationalcontextandhavingknowledgeofthesupportandmaterialsneeded for theirgood use in classis a tasktobeundertakenbytheentireschoolcommunity. Withsupportfromtheliterature review, themaindifficulties in integrating ICT in theschoolenvironmentwerefoundanddebated, as well as theneed for continuedteacher training andtheimportanceofimplementingpublic policies aimedatschoolPhysicalEducation.
\end{abstract}

KEYWORDS:Schoolphysicaleducation; ICT; Challenges; Teacher training; Pedagogicalpractice

\section{Reflexiones sobre laintegración de las TIC em La Educación Física escolar}

\section{RESUMEN}

Este ensayotiene como objetivo explicar losdesafíos que enfrentanlos docentes y lasinstituciones educativas enelproceso de implementación de las TIC enlasescuelas y enlapráctica pedagógica del docente de Educación Física. Entender cómoutilizarlosenel contexto educativo y tenerconocimiento de lossoportes y materialesnecesarios para subuen uso enel aula es una tarea que debeemprender toda lacomunidad escolar. Conelapoyo de larevisión de la literatura, se encontraron y debatieronlasprincipalesdificultades de laintegración de las TIC enelámbito escolar, así como lanecesidad de una formación continua delprofesorado y laimportancia de implementar políticas públicas orientadas a laEducación Física escolar.

PALABRAS-CLAVE:Educación física escolar; TIC; Desafíos; Formación de profesores; Práctica pedagógica 


\section{INTRODUÇÃO'}

As investigações e os debates em relação às Tecnologias de Informação e Comunicação (TIC) e à Educação Física surgiram, no Brasil, no início da década de 1990 e ganharam força, principalmente, após a formação de grupos de trabalhos temáticos (GTT) vinculados ao Colégio Brasileiro de Ciências do Esporte e ao Congresso Brasileiro de Ciências do Esporte, a partir de 1997 (CARVALHO; HATJE, 1996; PIRES et al. 2008; PIRES; LAZZAROTTI FILHO; LISBÔA, 2012). Com efeito, o desenvolvimento científico e tecnológico ocorrido desde os anos 2000 contribuiu para a ampliação do contingente de pesquisadores e de grupos de estudos com enfoque em discussões e debates sobre as TIC e suas relações nos diferentes contextos da Educação Física.

$\mathrm{Na}$ atualidade, os avanços tecnológicos impulsionam mudanças em todas as esferas da vida humana, diversificando os processos de ensinar e aprender e o modo como os indivíduos relacionam-se com o conhecimento em uma sociedade que, cada vez mais, está a exigir sujeitos com formação ampla e capazes de se adaptar rapidamente a um mundo em constante evolução e transformação (PIRES, 2002; BARROS; BRIGHENTI, 2004; FERREIRA; CASTIGLIONE, 2018). ${ }^{2}$ Novos desafios são lançados às instituições educativas, a exemplo da formação de professores, especialmente no que se refere ao uso, à incorporação e à adequação das TIC a suas práticas pedagógicas (LEÓN-VALDEZ; CARCÍA-LOPEZ; CUEVAS-SALAZAR, 2021).

Essa realidade está a demandar da escola e dos professores a revisão de suas práticas e a adoção de outros formatos de ensino, mais afinados com o cotidiano dos alunos, que valorizem sua bagagem cultural e lhes possibilitem a significação de conceitos abordados durante $o$ desenvolvimento curricular (BARROS; BRIGHENTI, 2004). A Educação Física, como componente curricular obrigatório, é parte fundamental do processo de transformação das práticas desenvolvidas em âmbito escolar, pois as mídias e as TIC atuam diretamente sobre os conteúdos por ela tematizados.

As investigações relacionadas à Educação Física no contexto escolar revelam desafios no processo de implementação das TIC na prática pedagógica do professor, no tocante à infraestrutura (BIANCHI; PIRES; VANZIN, 2008; BIANCHI; PIRES, 2010; CHAMPANGNATTE; NUNES, 2011; TORRES et al., 2016; MEZZAROBA; MORAES, 2018; NARDON; GONZÁLEZ, 2019), à

\footnotetext{
${ }^{1}$ Esse ensaio faz parte da dissertação de mestrado intitulada "Tecnologias de Informação e Comunicação na prática pedagógica de professores de Educação Física da Rede Municipal de Ensino de Florianópolis”.

${ }^{2}$ A pandemia gerada pelo COVID-19, com epicentro inicial na China, alterou a vida das pessoas de forma abrupta, exigindo modificações nas relações sociais e, consequentemente, nas estruturas, nos usos e nas apropriações relacionadas às tecnologias, inclusive na Educação.
} 
formação inicial e continuada (BIANCHI; HATJE 2007; BIANCHI; PIRES, 2015; SILVEIRA; BRÜGGEMANN; BIANCHI, 2019), ao tempo para planejamento e à articulação das propostas (BIANCHI; PIRES, 2010; CHAMPANGNATTE; NUNES, 2011; TORRES et al., 2017), à capacitação profissional (BIANCHI; PIRES; VANZIN, 2008; CHAMPANGNATTE; NUNES, 2011; TORRES et al., 2016).

Considerando os desafios que o uso das TIC impõe à Educação, de modo geral, e à Educação Física, em particular, e as influências para a formação de professores daí derivadas, surge a necessidade de refletir sobre os processos de sua adoção e as consequentes implicações para a formação de professores e estudantes visando ao domínio e à apropriação crítica dos novos meios digitais (KENSKI, 2007).

Nesse contexto, o presente ensaio aborda alguns dos desafios encontrados por professores e instituições educacionais no processo de implementação das TIC tanto em âmbito escolar como na prática pedagógica do professor de Educação Física. As considerações sobre a formação inicial e continuada do professor de Educação Física em relação à (não) apropriação das TIC para uso no processo de ensino e aprendizagem estão intimamente ligadas aos desafios, contudo, por serem consideradas essenciais ao processo, são aqui abordadas separadamente. O objetivo desse estudo consiste em identificar os desafios e as possibilidades de integração das TIC nas práticas pedagógicas dos professores de Educação Física e refletir sobre eles.

Os estudos pautados na mídia-educação surgem como suporte teórico para esse ensaio. A mídia-educação pode ser compreendida como uma abordagem teórico-metodológica com características interdisciplinares que estabelece mediações pedagógicas na formação de um sujeito ativo, crítico e produtivo em relação às TIC e às mídias (FANTIN, 2006, 2011). Nos processos educacionais, a mídia-educação pode ser abordada sob três perspectivas: crítica, a qual considera educar sobre/para as TIC/Mídias; instrumental, que considera educar com as TIC/Mídias; expressiva-produtiva, que considera educar através das TIC/Mídias (BÉVORT; BELLONI, 2009; FANTIN, 2011).

Tendo em vista os pressupostos da mídia-educação, a abordagem do tema aqui proposto concentra a atenção sobre a integração das TIC no contexto da Educação Física escolar. O processo de seleção da literatura para a elaboração desse ensaio concentrou-se em estudos e proposições de relevância na temática, assim como em pesquisadores com expertise, considerados referências na comunidade acadêmica por desenvolverem investigações sobre as tecnologias e as mídias na Educação Física escolar. O ensaio está organizado em três partes: na primeira, são abordados os desafios encontrados pelas comunidades escolares no processo de integração das TIC na Educação Física; na segunda, são expostas considerações sobre as TIC na formação inicial do professor de 
Educação Física; na terceira, é analisado o processo de formação continuada dos professores de Educação Física para as TIC.

\section{DESAFIOS NA INSERÇÃO DAS TIC NA EDUCAÇÃO FÍSICA}

As TIC estão sendo rapidamente integradas e disseminadas nos diversos âmbitos da sociedade, porém as escolas encontram dificuldades em integrá-las ao processo de ensino e aprendizagem (ZANELLA; LIMA, 2017). Entre os desafios enfrentados pelas instituições escolares e pelos professores estão a falta de infraestrutura (CHAMPANGNATTE; NUNES, 2011; TORRES et al. 2016; SOARES; IMPOLCETTO, 2017; ZANELLA; LIMA, 2017); o pouco tempo para capacitação e integração das TIC às práticas educativas (TORRES et al. 2017; NARDON; GONZÁLEZ, 2019); a ausência de profissionais específicos e qualificados (ES et al. 2016); a resistência tanto das instituições gestoras (KAWASHIMA, 2008) como dos estudantes (BETTI, 2006). A ausência, na formação inicial e continuada, de preparação para o uso das TIC constitui um dos principais desafios que dificultam sua integração ao contexto educacional. Esse fato ficou evidenciado durante a pandemia advinda no ano de 2020, quando os profissionais da educação tiveram que se reinventar devido à mudança abrupta de aulas em modo presencial para aulas em modo remoto. Em consequência, quadro, giz, papel e outros suportes foram substituídos por ferramentas de áudio e vídeo e por plataformas educacionais. Tal situação trouxe consigo uma demanda de conhecimentos para a qual a formação em TIC poderia ter preparado e, por conseguinte, diminuído as barreiras surgidas devido a tão repentina alteração.

Muito embora a inserção das TIC no em âmbito escolar não tenha a pretensão de solucionar todos os problemas dos processos de ensino e aprendizagem, a disponibilização de infraestrutura e de recursos tecnológicos e sua devida manutenção mostram-se imprescindíveis para efetivar a inclusão digital no contexto educacional, sendo eles, na atual conjuntura, ainda mais importantes. Apesar das políticas públicas voltadas para a implementação de recursos tecnológicos na escola, como o Programa Nacional de Tecnologia Educacional (ProInfo) e Um Computador por Aluno (UCA), estudos sobre a educação (física) mostram relatos de professores que ressaltam as dificuldades enfrentadas em relação ao acesso e ao uso das TIC no cotidiano da docência.

No tocante à infraestrutura, dentre os principais fatores considerados como impeditivos para o uso das TIC na prática pedagógica estão falta de espaço físico adequado; dificuldades em relação ao suporte e à manutenção de equipamentos e da rede; quantidade mínima de equipamentos para desenvolver as atividades (BIANCHI; HATJE, 2007; BIANCHI; PIRES; VANZIN, 2008; BIANCHI; PIRES, 2010; CHAMPANGNATTE; NUNES, 2011; TORRES et al., 2016; SOARES; 
IMPOLCETTO, 2017; DINIZ; DARIDO, 2015; MEZZAROBA; MORAES, 2018; NARDON; GONZÁLEZ, 2019). Diniz e Darido (2015) investigaram seis professores de Educação Física de um município do interior de São Paulo, a fim de avaliar a possibilidade de um blog educacional embasar os conteúdos a serem desenvolvidos nas aulas. A ausência de recursos tecnológicos em condições de uso e de espaço disponível para realização das proposições pedagógicas exigiram adequações à realidade das unidades educativas (DINIZ; DARIDO, 2015). Em uma sociedade que 'respira' tecnologia, torna-se inviável um ensino que, sem um suporte básico mínimo, busque dialogar com as necessidades socioculturais e pedagógicas de educandos e educadores.

A dificuldade atribuída à falta de disponibilidade de recursos tecnológicos em quantidade mínima e em funcionamento foi evidenciada por Nardon e González (2019), na investigação realizada com estudantes do terceiro ano do ensino fundamental de uma escola municipal de Porto Ferreira - SP. No transcorrer da observação, mesmo os equipamentos tendo sido conferidos com antecedência, no momento de utilizá-los havia um número reduzido de computadores em funcionamento e a lousa digital não funcionava, seja devido ao mau uso, seja por falta da necessária manutenção. No contexto da Rede Municipal de Ensino de Florianópolis (RMEF), o pequeno número de computadores e o espaço reduzido para a estruturação da sala informatizada são relatados por Bianchi, Pires e Vanzin (2008) como fatores limitadores para as propostas pedagógicas, pois, no desenvolvimento das atividades analisadas, três ou quatro estudantes dividiam o uso do computador. Esses dados são reforçados por Fantin (2010), em cujo estudo 74\% dos professores do ensino fundamental da RMEF, de diferentes áreas de conhecimento, relataram a falta de infraestrutura e de acesso às TIC como as principais dificuldades encontradas. Na pesquisa de Ferreira (2017), os professores de Educação Física de três redes municipais de ensino do estado de São Paulo consideraram a falta de infraestrutura e de recursos tecnológicos, a pouca manutenção dos equipamentos, a internet de baixa qualidade como pontos que dificultam a utilização das TIC na prática pedagógica.

A investigação de Sebriam (2009), 52\% dos professores de Educação Física, que atuavam em escolas municipais de Londrina, relataram a falta de recursos tecnológicos para uso nas práticas pedagógicas. Para Torres et al. (2016), os professores investigados da rede pública municipal de Fortaleza atrelam o pouco uso dos computadores na prática pedagógica à falta de estrutura, ressaltando-se que cinco das 39 escolas investigadas não possuíam sala de informática. Da mesma forma, Ferreira (2014) encontrou dificuldades relativas à falta de manutenção da sala de informática e à carência de estrutura física e de recursos adequados, ao propor aulas de Educação Física com jogos digitais, em uma escola estadual do município de Rio Claro - SP. Percebe-se que, mesmo com políticas públicas voltadas para a implementação de tecnologias na ambiência escolar, a falta 
dessas tecnologias é relatada de forma recorrente como um fator limitador ao uso das TIC nas escolas, dificultando significativamente, portanto, o desenvolvimento de atividades pedagógicas associadas às tecnologias.

No estudo de Ferreira (2014), ficaram evidenciadas a reduzida quantidade e a pouca qualidade dos aparatos tecnológicos disponibilizados, salientando-se que a utilização da sala de informática estava inviável devido à falta de manutenção e à dificuldade de acesso à internet, o que provocou inclusive alterações nas estratégias de ensino propostas pelo estudo. Mesmo as escolas que dispõem de recursos tecnológicos evidenciam dificuldades relacionadas ao número reduzido de equipamentos, à carência de manutenção, à falta de organização e de planejamento em relação ao uso da sala - pontos que desmotivam o uso das tecnologias pelos professores (CHAMPANGNATTE; NUNES, 2011, FERREIRA, 2017) Ao considerar a disponibilidade das TIC na escola, é imprescindível cuidar de sua manutenção e mesmo da troca de equipamentos, visando alavancar o desenvolvimento de práticas de ensino que permitam aos estudantes apropriarem-se, de maneira crítica e criativa, dos meios tecnológicos e informacionais (BELLONI, 2010).

A disponibilidade de infraestrutura e de recursos tecnológicos em quantidade suficiente que permita o desenvolvimento de práticas educativas com uso das TIC são questões a se avançar nas instituições educativas. $\mathrm{Na}$ pandemia de Covid-19, foi identificada a desigualdade de acesso às tecnologias, principalmente por estudantes, exigiu dos professores a preparação de material impresso, a fim de permitir o acesso aos conteúdos por todos os estudantes (GODOI et al., 2021). Além de estrutura física apropriada para receber recursos tecnológicos e implementar tecnologias, são necessárias tanto sua manutenção como a orientação da comunidade escolar quanto ao manuseio e uso adequados dos equipamentos, os quais apresentam vida útil limitada. A presença de recursos em quantidade suficiente e de boa qualidade contribui para a democratização do acesso às tecnologias, favorecendo principalmente aqueles estudantes que não têm acesso a elas fora da escola. Torna-se, pois, importante a implementação de políticas públicas que realmente se efetivem na prática.

No âmbito escolar, o professor depara-se com demandas vinculadas ao processo de ensino e de aprendizagem, assim como à gestão de questões administrativas referentes ao componente curricular. Nesse contexto, a carga horária elevada, o número de aulas e a conseqüente falta de tempo dos professores têm se configurado como empecilho tanto para o planejamento de atividades com uso das TIC como a participação em cursos de capacitação (BIANCHI; PIRES, 2010; CHAMPANGNATTE; NUNES, 2011; TORRES et al., 2017; FERREIRA, 2017). Saliente-se 
também que conhecer compreender e apropriar-se das TIC e suas linguagens, visando agregá-las às práticas pedagógicas, é algo processual e lento (BIANCHI; PIRES, 2010).

Durante a pandemia da COVID-19, os professores, de forma emergencial, tiveram que se adaptar ao modo remoto e, por consequência, planejar suas aulas em plataformas digitais, com recursos audiovisuais, muitas vezes utilizando aplicativos diversos para a elaboração de seu material didático. Apesar de a pandemia ser um acontecimento tão devastador, um dos aprendizados que ela trouxe é a importância da integração das TIC no planejamento das aulas, o que, no retorno ao modo presencial, estará mais presente no dia a dia do planejamento pedagógico (GODOI et al. 2021).

A incorporação das tecnologias ao planejamento e sua articulação à prática pedagógica exigem aumento do tempo dedicado à organização desses processos (TORRES et al. 2017; NARDON; GONZÁLEZ, 2019). Na pesquisa de Champangnatte e Nunes (2011), os professores de três escolas municipais do Rio de Janeiro vinculam o não uso das TIC à carga horária elevada, o que dificulta o planejamento das atividades com uso das tecnologias e a participação em cursos de capacitação. De forma semelhante, Bianchi e Pires (2010), consideram o elevado número de aulas como um fator impeditivo para a elaboração de propostas colaborativas e interdisciplinares, inclusive no tocante às TIC na prática pedagógica. No estudo de Fantin (2010), 48\% dos professores relataram a falta de tempo como fator impeditivo para aprenderem a usar as TIC. Em Mello e Branco (2011), o percentual sobe para 70\% dos professores indicando a falta de tempo para preparar suas aulas integradas às TIC.

A formação inicial e continuada insuficiente - e, por vezes, inexistente - relativa ao uso dos recursos tecnológicos na prática pedagógica, contribui para a resistência dos professores em relação à adoção das TIC (BIANCHI; PIRES; VANZIN, 2008; BIANCHI; PIRES, 2010). Com efeito, o processo de implementação das TIC exige a reestruturação organizacional das escolas, a fim de que o professor disponha de tempo e de condições físicas e materiais para participar das capacitações e para elaborar práticas pedagógicas com as TIC de forma interdisciplinar, articulada e colaborativa. Para Sebriam(2009), a formação continuada deve acontecer, no âmbito escolar, por meio da criação de um espaço de aprendizado autônomo, colaborativo e com assessoramento ao professor. A realização de cursos à distância é sugerida por Ferreira (2017) como outra possibilidade de formação docente, pois permite maior flexibilidade de tempo e local para participar das formações.

A falta de um profissional capacitado que disponibilize suporte técnico para os professores agregarem as práticas educativas às TIC e nas salas informatizadas, também se configura como um desafio aos docentes (TORRES et al. 2016). A importância da participação de um profissional capacitado foi evidenciada por Bianchi e Pires (2010), em cuja pesquisa as professoras da RMEF 
não encontraram, na experiência pedagógica desenvolvida, dificuldades no manuseio das TIC, haja vista que tiveram formação para o uso dos recursos e contaram com suporte técnico sempre que necessário. A presença de um profissional com conhecimento sobre o uso das tecnologias na educação possibilita a formulação de novas estratégias pedagógicas, que usem as TIC no processo de ensino e de aprendizagem dos conteúdos curriculares (BIANCHI; PIRES; VANZIN, 2008; CHAMPANGNATTE; NUNES, 2011; TORRES et al., 2016). A integração das TIC na escola requer que o professor conheça suas diferentes formas, tenha constante atualização, seja assessorado por um profissional da área tecnológica, tendo em vista as constantes mudanças e aperfeiçoamentos que ocorrem no setor tecnológico.

Em determinados contextos, a implementação e o uso das TIC na prática pedagógica podem encontrar resistência em diferentes instâncias das instituições educativas e, por conseguinte, limitar e restringir a adoção de determinadas tecnologias. Os estados de Santa Catarina, Rio de Janeiro, Rio Grande do Sul e o Distrito Federal, dispõem de leis estaduais que não permitem o uso de celular e, em alguns casos, também de outros dispositivos móveis em sala de aula. O estado de São Paulo tinha uma lei semelhante, porém, em 2017, nela foi incluída uma ressalva permitindo o uso dos dispositivos móveis em atividades com finalidade pedagógica. As justificativas para o impedimento da utilização de dispositivos móveis em sala de aula têm por embasamento a consideração de que eles podem afetar o processo de ensino e de aprendizagem.

A falta de compreensão e de entendimento das equipes gestoras de que as TIC podem se articular com os conteúdos da Educação Física aparece como outra dificuldade enfrentada pelos professores (FERREIRA, 2017). No estudo de Nardon e González (2019), os smartphones seriam utilizados como estratégia didática, no entanto isso foi impedido pela direção da escola com a justificativa de haver a possibilidade de os dispositivos móveis dos estudantes serem danificados e, por consequência, causarem problemas com as famílias, além de poderem atrapalhar o andamento das aulas. Em contrapartida, em Patrinhani, Magnoni e Prado Júnior (2017), o uso de smartphones permitiu aos estudantes realizarem pesquisas sobre as paraolimpíadas, pois a escola não dispunha de recursos (computadores) suficientes para todos os estudantes.

Intervenções dessa natureza evidenciam a importância de se pensar o emprego das tecnologias digitais para além de um mero recurso. Torna-se, pois, essencial um planejamento pedagógico que valorize as experiências e os saberes dos alunos, possibilitando o uso das TIC como meio facilitador da aprendizagem e de significação de conhecimentos adquiridos na escola. Mostrase essencial o desenvolvimento de um trabalho articulado, colaborativo e interdisciplinar, de forma a transpor os desafios enfrentados pela comunidade escolar e a ampliar a compreensão sobre a utilização das TIC no processo de ensino e de aprendizagem. 
Um agravante quanto ao uso das TIC nas aulas de Educação Física refere-se à representação que se tem dessa disciplina, considerada de cunho essencialmente 'prático', esvaziada de conteúdo, o que ocasiona a fragmentação do ensino e gera hierarquização entre as disciplinas que compõem a grade curricular (BIANCHINI; PIRES, 2016; FERREIRA, 2017). A produção do jornal da Educação Física, relatada no estudo de Kawashima (2008), surgiu da necessidade de mostrar as contribuições conceituais que a Educação Física pode oferecer para a formação dos estudantes, pois tal componente curricular fora excluído pela gestão da escola de um projeto de leitura que englobava os demais componentes curriculares. Durante a realização do projeto, o envolvimento e o reconhecimento da comunidade escolar ficaram evidenciados, principalmente em relação às contribuições que a produção midiática propiciou para a construção de conceitos que dialogam com a prática da área e que são importantes na formação dos estudantes (KAWASHIMA, 2008).

A proposta curricular de Florianópolis (2016) considera que as práticas com as TIC estão presentes em todos os componentes curriculares, sendo "indispensáveis e indissociáveis a/de todas as áreas de conhecimento" na educação dos sujeitos para o pleno exercício da cidadania na cultura digital (FLORIANÓPOLIS, 2016, p. 46). Nessa perspectiva, a Educação Física não apenas pode como também deve articular o uso das TIC e das mídias no ensino de seus conteúdos, sob o argumento de assim contemplar a formação do sujeito para o exercício da cidadania em sua plenitude. É, além disso, uma oportunidade de mostrar aos diferentes sujeitos da comunidade escolar que a Educação Física não se trata de prática por prática, mas envolve saberes e fazeres em relação às práticas expressivas corporais desenvolvidas ao longo da história humana.

A presença das TIC nas aulas de Educação Física, pode gerar certa resistência dos estudantes quando utilizadas para o desenvolvimento de proposições de cunho conceitual (DINIZ; RODRIGUEZ; DARIDO, 2012). Em Betti (2006), os estudantes dos anos finais do ensino fundamental e do ensino médio de escolas públicas e privadas demonstraram certa resistência inicial ao serem propostos conteúdos conceituais em sala, principalmente nas etapas de ensino em que a Educação Física tinha número reduzido de horas-aula. Nesse contexto, os estudantes apresentam dificuldades em compreender que a Educação Física não é apenas praticar movimentos corporais sistemáticos, mas que ela engloba também conceitos, valores e atitudes. Para Batista e Betti (2005), a Educação Física não deve se limitar à prática, mas abordar questões conceituais, atitudinais e temáticas relacionadas às práticas corporais. O uso e a forma de utilização das tecnologias nas aulas depende das estratégias pedagógicas e dos objetivos definidos pelo professor de acordo com o planejamento. Salienta-se que o conteúdo determina a TIC a ser utilizada e não o contrário (BETTI, 2006), sendo os instrumentos tecnológicos importantes ferramentas de mediação 
entre professores e estudantes, fundamental para a produção do conhecimento (MARCOLLA; MORO, 2021).

Ao discorrer sobre os desafios enfrentados na integração das TIC à Educação Física escolar, o presente ensaio não tem a pretensão de limitar ou suprimir outras questões não elencadas aqui, mas visa pautar os principais desafios revelados pela literatura. Mapear, compreender e analisar os desafios encontrados pelos professores em seu dia a dia possibilita refletir sobre diferentes alternativas, quer para transpô-los quer para fazer profícuo uso de TIC e mídias em âmbito escolar.

\section{APONTAMENTOS SOBRE A FORMAÇÃO INICIAL EM EDUCAÇÃO FÍSICA PARA O USO DE NOVAS TECNOLOGIAS}

O desenvolvimento tecnológico enseja novas possibilidades ao processo educativo, porém também apresenta inúmeros desafios, especialmente em relação à formação dos professores para adoção das TIC. Nesse cenário, o processo formativo dos professores tornou-se tema de diversos estudos e investigações, objetivando compreender e analisar a forma como as instituições educativas abordam as TIC na formação inicial (BIANCHI; HATJE, 2007; BIANCHI; PIRES, 2015; SOUSA; RIZZUTI; BORGES, 2016; SILVEIRA; BRÜGGEMANN; BIANCHI, 2019) e continuada de professores (BIANCHI; PIRES, 2010; TORRES et al. 2016; TORRES et al. 2017).

As instituições formadoras precisam preparar professores com capacidade de integrar as TIC as suas práticas, através do desenvolvimento de competências técnicas, críticas e criativasprodutivas em relação às mesmas (BIANCHI, 2014). Dessa maneira, a formação dos professores sob a perspectiva da mídia-educação (BELLONI, 2001; FANTIN, 2006), deve estar sempre atualizada e consoante com as demandas das instituições escolares, sociedade e formação continuada (FANTIN, 2006, 2012a). A formação do professor para a mídia-educação permite a integração das TIC à sua prática pedagógica na perspectiva de preparar o estudante para seu manuseio; para a leitura crítica e reflexiva de mensagens e conteúdos midiáticos; para a criação de mídias vinculadas aos conteúdos desenvolvidos.

No tocante ao processo formativo desenvolvido no ensino superior, Fantin (2012b) explica que a implementação das TIC nos currículos pode ocorrer de diferentes modos - disciplina curricular; transversal ao currículo; núcleos temáticos; outras proposições relacionadas às práticas culturais midiáticas - consolidando conteúdos sobre essa temática durante a formação acadêmica do futuro professor.

Os conhecimentos abordados na preparação do professor de Educação Física são disseminados pelos veículos midiáticos, de modo a influenciar a inteligibilidade da população sobre essas temáticas. As TIC precisam ser integradas à formação do professor, para que, autônoma, 
crítica e criativamente, ele consiga encadear tais recursos aos conteúdos específicos da área Estudos que analisaram os currículos de cursos de Educação Física verificaram serem reduzidas as propostas educativas em relação às TIC, as quais são desenvolvidas, principalmente, em uma perspectiva instrumental, ou seja, conforme o uso técnico dos recursos tecnológicos (SOUSA; RIZZUTI; BORGES, 2016; BIANCHI; PIRES, 2015; SILVEIRA; BRÜGGEMANN; BIANCHI, 2019). Em diminutas situações foram encontradas propostas envolvendo a Educação Física e as TIC, porém se tratavam de componentes curriculares optativos e específicos, mais vinculadas ao interesse pessoal e social de professores formadores (BIANCHI; PIRES, 2015; SILVEIRA; BRÜGGEMANN; BIANCHI, 2019). Percebe-se, pois, que mesmo as TIC e as mídias tendo influência sobre os conteúdos da Educação Física, elas são quase ignoradas e suas potencialidades são subutilizadas na formação de professores.

Em seu estudo Souza, Rizzuti e Borges (2016) verificaram que apenas 55\% dos cursos de licenciatura em Educação Física, em instituições federais mineiras, apresentavam componentes curriculares voltados para a educação para as TIC. Desses, 60\% veiculavam a dimensão crítica e apenas um curso, a dimensão produtiva da mídia-educação. Silveira, Brüggemann e Bianchi (2019), ao analisarem os cursos de licenciatura em Educação Física oferecidos nas universidades federais brasileiras, encontraram resultados semelhantes. Dos 44 cursos de Educação Física analisados, apenas 21 apresentaram um ou mais componentes curriculares voltados à educação para TIC e mídias, sendo nove componentes curriculares obrigatórios e 19 optativos. Dos componentes curriculares ofertados, 13 focavam a dimensão instrumental, 11 tinham características de dimensão crítica e cinco estavam voltados para a dimensão produtiva da mídia-educação.

A inserção das TIC, no currículo acadêmico, como uma disciplina pode garantir sua presença e seu fortalecimento no contexto de formação docente, possibilitando então pensar e articular outras formas de sua abordagem no currículo (FANTIN, 2012; SOUZA et al. 2016). Os componentes curriculares presentes nos cursos de licenciatura em Educação Física voltados à educação para as TIC mostram-se distantes e isolados, sem apresentar ligação com as demais disciplinas do curso (SOUZA; RIZZUTI; BORGES, 2016), dificultando, portanto, a junção das TIC e suas relações com os diferentes conteúdos da área. Sob essa ótica, torna-se importante que os componentes curriculares que abordam e desenvolvem a educação para as TIC não fiquem restritos ao formato disciplinar, mas se encadeiam com os outros componentes de forma interdisciplinar, transversal e colaborativa (SOUZA; RIZZUTI; BORGES, 2016). Isso permitirá ao professor pensar, elaborar e reelaborar suas práticas pedagógicas, integrando as TIC aos conteúdos da área, nas dimensões crítica e produtiva, ultrapassando o mero uso instrumental. 
As instituições que ofertam componentes curriculares que desenvolvem proposições em relação às TIC nas dimensões crítica-reflexiva e/ou expressiva-produtiva contam com docentes e pesquisadores que investigam as TIC na Educação Física, através da percepção sociocultural (SILVEIRA; BRÜGGEMANN; BIANCHI, 2019; BIANCHI; PIRES, 2015). Nesse contexto, a presença e o desenvolvimento de componentes curriculares e demais proposições educativas ficam vinculados à presença de um profissional qualificado e não a um projeto pedagógico institucional (BIANCHI; 2014; FANTIN, 2012a). É preciso, portanto, instituir diretrizes que permitam encurtar o distanciamento entre o ensino superior e as TIC e mídias, de modo que essa abordagem esteja presente de maneira generalizada nos currículos dos cursos de formação de professores.

O currículo na formação inicial, mesmo em uma sociedade midiatizada, mostra dificuldades de se pensar a formação de um professor que dialogue com as tecnologias. No estudo de Oliveira et al. (2020), percebe-se que, embora os discentes do curso de licenciatura em Educação Física de uma universidade federal compreendam a importância das TIC no processo de ensino, não se sentem preparados para fazer uso dessas ferramentas nas aulas. Em contraponto, as abordagens das TIC de modo disciplinar, juntamente com proposições transversais ao currículo, inclusive através de eventos e grupos de estudos, possibilitam a formação de estudantes/professores autônomos para o uso das TIC (SOUZA; MENDES, 2014).

A formação inicial revela-se muito aquém de suas possibilidades e potencialidades, quando se visa à formação de professores capazes de atuar com as TIC. As propostas, as matrizes curriculares e os projetos político pedagógicos dos cursos de Educação Física, evidenciam-se pouco permeáveis às TIC, atribuindo ênfase a suas características instrumentais-metodológicas, havendo escassas propostas para seu uso nas perspectivas crítica e produtiva (BIANCHI; HATJE 2007; BIANCHI; PIRES, 2015; SILVEIRA; BRÜGGEMANN; BIANCHI, 2019). As diferentes abordagens de inserção da mídia-educação no currículo foram discutidas por Fantin (2012b) a qual concluiu que, independente da forma de abordagem curricular das TIC, é crucial que teoria e a prática estejam articuladas, a fim de facilitar a aplicabilidade pedagógica.

A reestruturação dos currículos dos cursos de formação de professores com inclusão do preparo para uso das TIC mostra-se essencial. Isso permitirá aos futuros professores relacionaremse de forma crítica, produtiva e fluente e melhor exercerem o papel de mediador, problematizador e articulador das informações recebidas pelos estudantes por meio das TIC, sendo, pois, novas competências do professor na Educação inserido na cultura digital (BELLONI, 2010; SOUZA; RIZZUTI; BORGES, 2016; TORRES et al., 2017).

Por certo que as dificuldades ultrapassam a estrutura curricular e englobam falta de incentivo na formação de formadores em relação aos conteúdos das TIC; infraestrutura deficiente; 
pouco desenvolvimento de práticas educativas com, para e através das TIC (BIANCHI; HATJE, 2007; BIANCHI, 2014). Nesse contexto, a implementação de disciplinas e/ou práticas interdisciplinares mostra-se importante, sendo essenciais o desenvolvimento e a implementação de políticas públicas que lhes deem suporte.

\section{APONTAMENTOS SOBRE A FORMAÇÃO CONTINUADA EM EDUCAÇÃO FÍSICA PARA O USO DE NOVAS TECNOLOGIAS}

No tocante à formação continuada, especialmente quando pensada a formação do professor de Educação Física visando ao uso das TIC em suas práticas pedagógicas, percebe-se haver carência de ofertas pertinente a isso. Os professores de Educação Física não se sentem preparados para desenvolver práticas educativas com o uso das tecnologias (MENDES, 2008; SEBRIAM, 2009; OLIVEIRA et al., 2020). A insegurança está associada, entre outras dimensões, à falta de formação adequada para a apropriação técnica e pedagógica dos recursos midiáticos e tecnológicos (MENDES, 2008; SEBRIAM, 2009). Uma formação continuada específica torna-se essencial para que o professor seja capaz de dialogar com a cultura digital, o que contribuirá para a qualificação docente e a aprendizagem dos estudantes.

A formação continuada ocorre principalmente por autodidaxia (SEBRIAM, 2009; TORRES et al., 2017) palestras, seminários e conferências, sendo que aqueles que buscam tal formação vislumbram adquirir e ampliar seus conhecimentos, de modo a qualificar sua prática pedagógica. Contudo, um significativo número de professores não realiza nenhum tipo de formação (TORRES et al., 2017). No estudo de Sebriam (2009), a formação continuada de 45,3\% dos professores de Educação Física realizou-se por autoformação; de 40\%, através de auxílio de amigos/familiares; de $17,3 \%$ por meio de cursos de formação oportunizados pela secretaria de educação. A autora percebeu que apenas uma pequena parcela de professores faz uso das TIC em sua prática pedagógica, o que possivelmente está relacionado tanto ao pequeno número de professores $(26,7 \%)$ que receberam formação sobre o tema, quanto à falta de recursos tecnológicos.

De modo geral, a formação continuada em Educação Física tem abordado os conteúdos da área, mas sem estabelecer qualquer relação com o uso das tecnologias (FERREIRA; BRENDATH; BASEI, 2016; TORRES et al., 2017), sendo esse um dos motivos para os professores não frequentarem a formação, acrescido da falta de tempo e de recursos tecnológicos na escola (TORRES et al., 2017; FERREIRA, 2017). Quando oportunizados cursos para as TIC, eles raramente dispõem de conteúdos passíveis de serem transpostos para a prática docente, apresentando caráter técnico e/ou divulgando exposições superficiais sobre os recursos a serem utilizados (FERREIRA; BRENDATH; BASEI, 2016; TORRES et al., 2017). 
No estudo de Mendes (2008), os professores relataram que a formação disponibilizada pela instituição à qual estão vinculados não lhes traz segurança nem conhecimentos suficientes para a realização de proposições com as TIC. O investimento em formações específicas, que aproximem os conhecimentos da Educação Física das TIC, evidencia-se fundamental para que o professor seja capaz de reconhecer possibilidades e desafios de sua adoção na prática pedagógica (SEBRIAM, 2009; TORRES et al., 2017) e busque adequar o ensino às demandas estudantis e ao cotidiano profissional, sempre mais influenciados pelos meios tecnológicos. Na medida em que o professor estabelece novos conhecimentos e significados em relação às tecnologias, consegue desenvolver proposições educativas de maneira segura e qualificada (TOCANTINS; WIGGERS, 2013, FERREIRA, 2017).

O professor necessita conhecer meios, linguagens, mensagens e conteúdos, a fim de compreender e entender as TIC e delas fazer uso no processo de ensino e de aprendizagem (SEBRIAM, 2009; SOUZA; RIZZUTI; BORGES, 2016) visando contribuir para a formação de estudantes críticos, criativos e autônomos em relação às tecnologias. Entende-se que a integração das TIC nas aulas de Educação Física representa a possibilidade de desenvolver novos aprendizados e conhecimentos por meio de diferentes linguagens. Estudos demonstram que a integração das TIC à Educação Física escolar, sob a perspectiva de mídia-educação, não descaracteriza a especificidade do componente curricular (OLIVEIRA; PIRES, 2005; MENDES, 2008; BIANCHI; PIRES, 2010).

Para Mendes (2008), a formação continuada é mais eficiente quando considera o contexto escolar e os saberes e fazeres de domínio do professor, sendo essencial a vivência, a fim de possibilitar o avanço nas práticas pedagógicas. Ao propor a realização de uma formação para mídia-educação, Bianchi (2009) relata a ampliação nos aprendizados e conhecimentos dos professores em relação às TIC, assim como no processo de ensino e de aprendizagem da Educação Física. Silveira e Pires (2019) propõem aos professores participantes da formação a reflexão sobre o núcleo específico de formação continuada do curso de especialização "Educação na Cultura Digital". Tal estudo apresenta alguns indicativos a serem considerados nas formações: diálogo com a realidade e as necessidades de cada componente curricular; proposições comunicativas que aproximem os atores presentes na formação dos professores; consideração dos diferentes contextos ao pensar na integração das TIC às aulas, de modo a possibilitar o desenvolvimento de novos arranjos pedagógicos. Os estudos citados corroboram que a formação para as TIC desenvolvida no contexto específico do componente curricular contribui para a transformação da prática pedagógica, tornando-a mais coerente com a realidade social e cultural dos estudantes.

O estudo de Ferreira (2017) propôs a realização de um curso de formação para professores de Educação Física, visando aprofundar o conhecimento e refletir sobre o uso das TIC na prática 
pedagógica. A autora explicita que, inicialmente, os professores demonstraram receio em fazer uso das tecnologias, principalmente pela falta de conhecimento técnico e de confiança no uso das ferramentas. No entanto, ao término do curso mostraram novas e importantes percepções e reflexões sobre as possibilidades de integração das TIC às aulas.

O curso de formação de professores para as TIC possibilitou elencar alguns pontos: para um aprendizado significativo, devem ser levados em consideração os contextos e as particularidades de cada professor; cursos presenciais e à distância possibilitam participação mais efetiva dos professores, pois oportunizam sua realização em diferentes momentos e espaços; a delimitação e a compreensão do conteúdo a ser ensinada, a especificação do objetivo da proposição e das funções das TIC facilitam a integração das tecnologias às aulas de Educação Física; o processo formativo demanda tempo e necessita de momentos teórico-práticos reflexivos em relação ao processo de ensino e de aprendizagem; para uma prática transformadora o professor deve ter conhecimento sobre a tecnologia a ser utilizada e o curso deve focar o processo progressivo da prática pedagógica e do método de ensino (FERREIRA, 2017).

A formação do professor para o uso das TIC nas práticas pedagógicas, considerando as demandas da cultura digital, torna-se imprescindível. Nesse sentido, o professor precisa compreender os diferentes discursos, significados e mensagens das TIC e das mídias para integrálas às práticas educativas e contribuir para o processo de aprendizagem dos estudantes (TORRES et al., 2017; TORRES et al., 2016; BIANCHI; PIRES, 2015).

Considerando os desafios elencados, entende-se que o processo formativo precisa superar a simples oferta de cursos técnicos, destinados a apresentar uma gama de recursos tecnológicos aos professores. Há necessidade de se pensarem ações formativas que concebam o professor como sujeito da própria formação, pesquisador e produtor de conhecimentos, oferecendo a ele oportunidades e condições de aprender e refletir, autônoma, crítica e criativamente, sobre as implicações das TIC no desenvolvimento de sua ação pedagógica.

\section{CONSIDERAÇÕES FINAIS}

Considerando a literatura investigada, a integração das TIC ao processo de ensino e de aprendizagem da Educação Física escolar impõe muitos desafios de naturezas diversas. A falta de infraestrutura, de recursos tecnológicos, de manutenção apropriada dificulta o desenvolvimento de proposições no âmbito do componente curricular e das instituições educativas. A presença de um profissional capacitado para assessorar e dar suporte ao professor, no fazer técnico-pedagógico, enriquece e facilita o trabalho a ser desenvolvido. A falta de tempo do professor, devido às 
inúmeras demandas, e a resistência da comunidade escolar ao uso das TIC nas práticas pedagógicas da Educação Física são questões que, em diferentes contextos, tornam-se desafios a serem transpostos.

Aliada a essas questões, a formação inicial do professor de Educação Física demonstra estar em descompasso com as necessidades formativas da sociedade contemporânea, sendo poucos os cursos que abordam as TIC em suas práticas curriculares. E, quando presentes nos currículos, estão presentes de forma diminuta em disciplinas voltadas para o desenvolvimento técnico-instrumental das TIC. Desse modo, a sugestão de proposições críticas e criativas fica dependente da presença de professores e pesquisadores dispostos a assumir essa frente nos cursos de formação de professores, descaracterizando a ideia de um projeto institucional ou vinculado a políticas educacionais.

No tocante à formação continuada, a apropriação de conhecimentos relacionados às TIC para a prática pedagógica ocorre, sobretudo por meio da autoformação, opção que possivelmente esteja relacionada à baixa oferta de proposições pensadas na formação do professor de Educação Física para o uso das TIC. Entende-se que as mudanças no modo de conceber e lidar com as TIC em âmbito escolar é um processo ainda em construção. Trata-se de uma realidade complexa, marcada por elementos culturais, sociais e políticos que permeiam a prática pedagógica e a formação dos professores. Acredita-se que a universidade e, em particular, os cursos destinados à formação de professores têm uma importante contribuição a dar seja com a ampliação das discussões sobre o currículo, seja com a oferta de cursos de formação continuada, seja com a realização de pesquisas e intervenções que tomem o trabalho docente um ponto de partida e de chegada dessas proposições.

Conclui-se que se torna necessário o desenvolvimento de estudos empíricos que abordem a articulação prática entre formação inicial, prática pedagógica e formação continuada, voltados ao uso qualificado e efetivo das TIC. Mostra-se também relevante aprofundar e refletir, por meio de estudos empíricos e teóricos, sobre as dificuldades vivenciadas por professores e instituições educativas na integração das TIC ao contexto escolar, visando compreender a realidade, e engendrar soluções para os desafios que se apresentam.

\section{REFERÊNCIAS}

BARROS, Daniela MelaréVeira; BRIGHENTI, Maria José Lourenção. Tecnologias da Informação e comunicação \& formação de professores: tecendo algumas redes de conexão. In: RIVERO, Cléia Maria L.; GALLO, Sílvio (Orgs.). A formação de professores na sociedade do conhecimento. Bauru, SP: Edusc, 2004. p. 125-144. (Coleção Educar). 
BATISTA, Sidnei Rodrigues; BETTI, Mauro. A televisão e o ensino da Educação Física na escola: uma proposta de intervenção. Revista Brasileira de Ciências do Esporte, Campinas, v. 26, n. 2, p. 135-148, jan. 2005. Disponível em:

http://revista.cbce.org.br/index.php/RBCE/article/view/152/161. Acesso em: 01 dez. 2021.

BELLONI, Maria Luiza. Mídia-Educação e Educação a Distância na formação de professores In: MILL, Daniel; PIMENTEL, Nara (Orgs.). Educação a Distância: desafios contemporâneos. São Carlos: EduFSCar, 2010. p. 245-265.

BELLONI, Maria Luiza. O que é mídia-educação. Campinas: Autores Associados, 2001.

BETTI, Mauro. Imagens em ação: uma pesquisa ação sobre o uso de matérias televisivas em programas de Educação Física do ensino fundamental e médio. Movimento, Porto Alegre, v. 12, n. 2, p. 95-120, maio/ago. 2006. https://doi.org/10.22456/1982-8918.2898.

BÉVORT, Evelyne; BELLONI, Maria Luiza. Mídia-Educação: conceito, história e perspectivas. Educação \& Sociedade, Campinas, v. 30, n. 109, p. 1081-1102, set./dez. 2009. https://doi.org/10.1590/S0101-73302009000400008.

BIANCHI, Paula. Formação em Mídia-Educação (Física): ações colaborativas na Rede Municipal de Florianópolis/Santa Catarina. 2009. 214f. Dissertação (Mestrado em Educação Física) - Programa de Pós-Graduação em Educação Física, Centro de Desportos, Universidade Federal de Santa Catarina, Florianópolis, 2009.

BIANCHI, Paula. Formação de professores e cultura digital: observando caminhos curriculares através da mídia-educação. 2014. 291f. Tese (Doutorado em Educação Física) -Programa de PósGraduação em Educação Física, Centro de Desportos, Universidade Federal de Santa Catarina, Florianópolis, 2014.

BIANCHI, Paula; HATJE, Marli. A formação profissional em Educação Física permeada pelas tecnologias de informação e comunicação no Centro de Educação Física e Desportos da Universidade Federal de Santa Maria. Pensar a prática, Goiânia, v. 10, n. 2, p. 291-306, 2007.https://doi.org/10.5216/rpp.v10i2.1097.

BIANCHI, Paula; PIRES, Giovani de Lorenzi. Cultura digital e formação de professores de Educação Física: estudo de caso na Unipampa. Movimento, Porto Alegre, v. 21, n. 4, p. 1025-1036, out./dez. 2015. https://doi.org/10.22456/1982-8918.53778.

BIANCHI, Paula; PIRES, Giovani de Lorenzi. Possibilidades para o ensino-aprendizagem com TICs na Educação Física Escolar: uma experiência com blogs. Cadernos de formação RBCE, Florianópolis, v. 1, n. 2, p. 45-55, mar. 2010. Disponível em:

http://revista.cbce.org.br/index.php/cadernos/article/view/982. Acesso em: 01 dez. 2021.

BIANCHI, Paula; PIRES, Giovani de Lorenzi; VANZIN, Tarcísio. As Tecnologias de Informação e Comunicação na Rede Municipal de Ensino de Florianópolis: possibilidades para a Educação (Física). Revista Linhas, Florianópolis, v. 9, n. 2, p. 56-75, jul./dez. 2008. Disponível em: https://www.periodicos.udesc.br/index.php/linhas/article/view/1372.Acesso em: 1 dez. 2021.

BIANCHINI, Leandro; PIRES, Giovani De Lorenzi. Educação Física, currículo, formação e cultura escolar: percepções de professores acerca de suas formações permanentes. In: BRUGGEMANN, 
Ângelo, Luiz; BIANCHI, Paula; SANTOS, Silvan Menezes dos. Pesquisa e formação em MídiaEducação (orgs.). Florianópolis: Tribo da Ilha, 2016, p. 98-119.

CARVALHO, Sérgio; HATJE, Marli. Proposta de desenvolvimento de um novo conhecimento na e para a Educação Física e a comunicação social no Brasil. Revista Brasileira de Ciências do Esporte, Campinas, v. 17, n. 3, p. 260-265, maio, 1996. Disponível em: http://revista.cbce.org.br/index.php/RBCE/article/view/858. Acesso em: 01 dez.2021.

CHAMPANGNATTE; DostoiewskiMariatt de Oliveira; NUNES, Lina Cardoso. A inserção das mídias audiovisuais no contexto escolar. Educação em Revista, Belo Horizonte, v. 27, n. 3, p. 1538, 2011. https://doi.org/10.1590/S0102-46982011000300002.

DINIZ, Irlla Karla dos Santos; DARIDO, Suraya, Cristina. Blog Educacional e o ensino das danças folclóricas nas aulas de Educação Física: aproximações a partir do currículo do estado de São Paulo. Movimento, Porto Alegre, v. 21, n. 3, p. 701-716, jul./set. 2015. https://doi.org/10.22456/1982$\underline{8918.53073 .}$.

DINIZ, Irlla Karla dos Santos; RODRIGUES, Heitor de Andrade; DARIDO, Suraya Cristina. Os usos das mídias em aulas de Educação Física escolar: possibilidades e dificuldades. Movimento, Porto Alegre, v. 18, n. 3, p.183-202, jul./set. 2012. https://doi.org/10.22456/1982-8918.27108.

FANTIN, Monica. Dos consumos culturais aos usos das mídias e tecnologias na prática docente. Motrivivência, Florianópolis, p. 12-24, 2010. https://doi.org/10.5007/\%25x.

FANTIN, Monica. Mídia-educação no currículo e na formação inicial de professores. In: FANTIN, Monica; RIVOLTELLA, PierCesare (orgs.). Cultura Digital e Escola: pesquisa e formação de professores. Campinas: Papirus, 2012a, p. 57-92.

FANTIN, Monica. Mídia-Educação no ensino e o currículo como prática cultural. Currículo sem fronteiras, v. 12, n. 2, p. 437-452, maio/ago. 2012b. Disponível em:

https://www.curriculosemfronteiras.org/vol12iss2articles/fantin.htm. Acesso em: $01 \mathrm{dez} .2021$.

FANTIN, Mônica. Mídia-Educação: aspectos históricos e teórico-metodológicos. Olhar de professor, Ponta Grossa, v. 14, n. 1, p. 27-40, 2011.

https://doi.org/10.5212/OlharProfr.v.14i1.0002.

FANTIN, Monica. Mídia-educação: conceitos, experiências e diálogos Brasil-Itália. Cidade Futura: Florianópolis, 2006.

FERREIRA, Aline Fernanda. As Tecnologias Digitais da Informação e Comunicação nas aulas de Educação Física: a formação continuada em serviço de professores da rede pública. 2017. $193 \mathrm{f}$. Tese (Doutorado em Desenvolvimento Humano e Tecnologias) - Programa de Desenvolvimento Humano e Tecnologias, Instituto de Biociências, Universidade Estadual Paulista, Rio Claro, 2017.

FERREIRA, Aline Fernanda. Os jogos digitais como apoio pedagógico nas aulas de Educação Física escolar pautadas no currículo do estado de São Paulo. 2014. 129f. Dissertação (Mestrado em Desenvolvimento Humano e Tecnologias) - Programa de Desenvolvimento Humano Tecnologias, Instituto de Biociências, Universidade Estadual Paulista, Rio Claro, 2014. 
FERREIRA, Erica Renata Gusmão.; BENDRATH, Eduardo Ângelo; BASEI, Andréia Paula. As TICs na Escola a partir da visão de professores de Educação Física de um município paranaense. Revista EducaOnline, Rio de Janeiro, v. 10, n. 1, p.75-94, jan.-abr., 2016 (sem acesso online)

FERREIRA, Giselle Martins dos Santos; CASTIGLIONE, Rafael Guilherme Mourão. TIC na educação: ambientes pessoais de aprendizagem nas perspectivas e práticas de jovens. Educação e Pesquisa, São Paulo, v. 44, p. 1-22, 2018. https://doi.org/10.1590/S1678-4634201702153673.

FLORIANÓPOLIS. Prefeitura Municipal. Secretaria Municipal de Educação. Proposta Curricular da Rede Municipal de Ensino de Florianópolis. Florianópolis, 2016

GODOI, Marcos; KAWASHIMA, Larissa Beraldo; GOMES, Luciane de Almeida; CANEVA, Chistiane. As práticas do ensino remoto emergencial de Educação Física em escolas públicas durante a pandemia de COVID-19: Reinvenção e Desigualdade. Revista Prática Docente. Cuiabá, v. 6, n. 1, p.1-12, jan/abr. 2021. http://doi.org/10.23926/RPD.2021.v6.n1.e012.id995.

KAWASHIMA, Larissa Beraldo. "Jornalzinho da Educação Física”: Relato de uma Experiência na Educação Física Escolar. Motrivivência, Florianópolis, Ano XX, n. 30, p. 143-157, jun. 2008. https://doi.org/10.5007/2175-8042.2008n30p143.

KENSKI, Vani Moreira. Educação e Tecnologias: o novo ritmo da informação. Campinas, SP: Papirus, 2007. (Coleção Papirus Educação).

LEÓN-VALDEZ, Rosário Berenice; CARCÍA-LOPEZ, Ramona Imelda; CUEVAS-SALAZAR, Omar. Nível de domínio de tecnologias de informação e comunicação em professores do ensino fundamental privado. Revista Ibero-Americana de Estudos em Educação, Araraquara, v. 16, n. esp. 1, p. 820-834, mar., 2021. https://doi.org/10.21723/riaee.v16iEsp.1.14917.

MARCOLA, Valdinei; MORO, TatieleBolson. As TIC no espaço escolar: uma análise da apropriação a partir das práticas docentes. Roteiro, Joaçaba, v. 46, p. 1-22, jan/dez. 2021.https://doi.org/10.18593/r.v46i.23875.

MELO, Sérgio Correa; BRANCO, Eguimara Selma. O uso das tecnologias de informação e comunicação nas aulas de Educação Física. In: X CONGRESSO NACIONAL DA EDUCAÇÃO EDUCERE, 2011, Curitiba. Anais [...]. Curitiba: Editora Universitária Champagnat, 2012. p. 29903000 .

MENDES, Diego. Luz, câmera e pesquisa-ação: a inserção da mídia-educação na formação continuada de professores de Educação Física. 2008. 201f. Dissertação (Mestrado em Educação Física) - Programa de Pós-Graduação em Educação Física, Centro de Desportos, Universidade Federal de Santa Catarina, Florianópolis, 2008.

MEZZAROBA, Cristiano; MORAES, Claudia Emília. Oficina pedagógica em esporte e mídia com professores de Educação Física. Cadernos de Formação RBCE, Florianópolis, v. 9, n. 2, p. 70-82, set. 2018. Disponível em: http://revista.cbce.org.br/index.php/cadernos/article/view/2334/1302. Acesso em: 01 dez. 2021.

NARDON, Tiago Aparecido; GONZÁLEZ, Fernando Jaime. Jogos e Brincadeiras: o ensino mediado pelas tecnologias da informação e comunicação. Motrivivência, Florianópolis, v. 31, n. 59, p. 1-14, 2019. https://doi.org/10.5007/2175-8042.2019e58147. 
OLIVEIRA, GéssycaTolomeu; MAZZI, Beatriz Leite; UNGHERI, Bruno Ocelli; CAMPOS, Priscila Augusta Ferreira; FERREIRA, Renato Melo. Escola x tecnologia: reflexões sobre a formação de professores de Educação Física. Caderno de Educação Física e Esporte, Marechal Cândido Rondon, v. 18, n. 1, p. 1-6, jan./abr. 2020. http://dx.doi.org/10.36453/23185104.2020.v18.n1.p17.

OLIVEIRA, Márcio Romeu Ribas; PIRES, Giovani de Lorenzi. O primeiro olhar: experiência com imagens na Educação Física escolar. Revista Brasileira de Ciências do Esporte, Campinas, v. 26, n. 2, p. 117-133, jan. 2005. Disponível em:

http://www.revista.cbce.org.br/index.php/RBCE/article/view/151. Acesso em: 01 dez. 2021.

PATRINHANI, GiseliFregolente; MAGNONI, Maria da Graça Mello; PRADO JUNIOR, Milton Vieira. Educação Inclusiva e Mídias: Práticas pedagógicas nas aulas de Educação Física Escolar. Revista da Associação Brasileira de Atividade Motora Adaptada, Marília, v. 18, n. 1, p. 77-92, 2017. https://doi.org/10.36311/2674-8681.2017.v18n1.07.p79.

PIRES, Giovani de Lorenzi. Educação Física e o discurso midiático: Abordagem Críticoemancipatória. Ijuí: Editora Unijuí, 2002.

PIRES, Giovani de Lorenzi; LAZZAROTTI FILHO, Ari; LISBÔA, Mariana Mendonça. Educação Física, mídia e tecnologias - Incursões, pesquisa e perspectivas. Kinesis, Santa Maria, v. 30, n. 1, p. 55-79, jan./jun. 2012. http://dx.doi.org/10.5902/010283085723.

PIRES, Giovani de Lorenzi; LISBOA, Mariana Mendonça; ANTUNES, Scheila; MEZZAROBA, Cristiano; MENDES, Diego Souza; SILVA, Karla Mathoso da; AZEVEDO, Victor Abreu. A pesquisa em Educação Física e mídia: pioneirismo, contribuições e críticas ao "Grupo de Santa Maria”. Movimento, Porto Alegre, v. 14, n. 03, p. 33-52, 2008.https://doi.org/10.22456/1982$\underline{8918.2543}$.

SEBRIAM, Débora Cristina da Silva. Utilização das Tecnologias da Informação e Comunicação no ensino da Educação Física. 2009. 184f. Dissertação (Mestrado em Engenharia de mídias para a Educação) - Programa Erasmus Mundus, Universidad Nacional de Educácion a distância de Madrid, Espanha, Universidade técnica de Lisboa, Portugal, Universidade de Poitiers, França, 2009.

SILVEIRA, Juliano; BRÜGGEMANN, Ângelo Luiz; BIANCHI, Paula. Formação de professores de Educação Física e tecnologias digitais de informação e comunicação (TDIC)/mídia: uma relação possível? Análise das propostas curriculares de universidades federais brasileiras. Motrivivência, Florianópolis, v. 31, n. 57, p. 1-19, jan./mar. 2019. https://doi.org/10.5007/2175-8042.2019e55308.

SILVEIRA, Juliano; PIRES, Giovani De Lorenzi. Formação continuada em educação física e tecnologias digitais: percepções dos professores participantes. Corpoconsciência, Cuiabá, v. 23, n. 02, p. 49-62, mai./ ago., 2019. Disponível em:

https://periodicoscientificos.ufmt.br/ojs/index.php/corpoconsciencia/article/view/8505. Acesso em: $01 \mathrm{dez} .2021$.

SOARES, D.C.; IMPOLCETTO, F.M. TIC nas relações étnico-raciais: limitações e possibilidades na Educação Física escolar para o Ensino Médio a partir do currículo do Estado de São Paulo. In: Congresso Internacional de Educação Física e Motricidade Humana, 10.; Simpósio paulista de Educação Física, 16., Rio Claro. Anais [...]. Rio Claro: UNESP, 2017. 
SOUSA, Galdino Rodrigues de; MENDES, Diego de Sousa. Mídias na formação em Educação Física: análise de uma disciplina optativa. Motrivivência, Florianópolis, v. 26, n. 43, p. 300-315, 12 nov. 2014. https://doi.org/10.5007/2175-8042.2014v26n43p300.

SOUSA, Galdino Rodrigues de; RIZZUTI, Elaine Valéria; BORGES, Eliane Medeiros. Educação para as TICs na formação em Educação Física: análises curriculares por meio da mídia-educação. Pensar a prática, Goiânia, v. 19, n. 3, jul./set. 2016. https://doi.org/10.5216/rpp.v19i3.39071.

SOUSA, Galdino Rodrigues; RIZZUTI, Elaine Valéria; BORGES, Eliane Medeiros; COSTA, Dimas de Paula. Mídia-educação nas universidades federais mineiras: mapeando a formação em educação física. Motrivivência, Florianópolis, v. 28, n. 47, p. 96, 25 maio 2016.

https://doi.org/10.5007/2175-8042.2016v28n47p96.

TOCANTINS, Geusiane Miranda de Oliveira; WIGGERS, Ingrid Dittrich. TIC e Educação do corpo: professores e suas apropriações. In: Congresso Brasileiro de Ciências do Esporte, 18.; Congresso Internacional de Ciências do Esporte, 5., 2013, Brasília. Anais [...]. Brasília: CBCE, 2013.

TORRES, Aline Lima; MOTA, Mabelle Maia; BARROS, Elainny Patrícia Lima; FERREIRA, Heraldo Simões. As tecnologias da informação e comunicação e a Educação Física Escolar: a realidade de professores da rede pública municipal de Fortaleza. Educação Temática Digital, Campinas, v. 18, n. 1, p. 198-214, jan./abr. 2016.https://doi.org/10.20396/etd.v18i1.8640601.

TORRES, Aline Lima; MOTA, Mabelle Maia; FERREIRA, Heraldo Simões; FERREIRA, Aline Fernanda; DARIDO, SurayaCristina.Formação Continuada para o uso das Tecnologias da Informação e comunicação-TICs: um estudo com professores de Educação Física de Fortaleza.TIC s \&EaD em Foco, São Luís, v. 3, n. 1, p. 54-72, jan./jun. 2017. Disponível em:

https://www.uemanet.uema.br/revista/index.php/ticseadfoco/article/view/169/232. Acesso em: 01 dez. 2021.

ZANELLA, Brenda Rafaela Devens; LIMA, Maria de Fátima Webber Prado. Refletindo sobre os fatores de resistência no uso das TICs nos ambientes escolares. Scientia cum Industria, Caxias do Sul, v. 5, n. 2, p. 78-89, 2017. http://dx.doi.org/10. 18226/23185279.v5iss2p78.

\section{NOTAS DE AUTOR}

\section{AGRADECIMENTOS}

Não se aplica

CONTRIBUIÇÃO DE AUTORIA.

Não se aplica

FINANCIAMENTO

Não se aplica.

\section{CONSENTIMENTO DE USO DE IMAGEM}


Não se aplica

\section{APROVAÇÃO DE COMITÊ DE ÉTICA EM PESQUISA}

Não se aplica

\section{CONFLITO DE INTERESSES}

Não se aplica

\section{LICENÇA DE USO}

Os autores cedem à Motrivivência - ISSN 2175-8042 os direitos exclusivos de primeira publicação, com o trabalho simultaneamente licenciado sob a Licença Creative Commons Attribution Non-Comercial ShareAlike (CC BY-NC SA) 4.0 International. Esta licença permite que terceiros remixem, adaptem e criem a partir do trabalho publicado, desde que para fins não comerciais, atribuindo o devido crédito de autoria e publicação inicial neste periódico desde que adotem a mesma licença, compartilhar igual. Os autores têm autorização para assumir contratos adicionais separadamente, para distribuição não exclusiva da versão do trabalho publicada neste periódico (ex.: publicar em repositório institucional, em site pessoal, publicar uma tradução, ou como capítulo de livro), com reconhecimento de autoria e publicação inicial neste periódico, desde que para fins não comerciais e compartilhar com a mesma licença.

\section{PUBLISHER}

Universidade Federal de Santa Catarina. Programa de Pós-Graduação em Educação Física. LaboMídia - Laboratório e Observatório da Mídia Esportiva. Publicado no Portal de Periódicos UFSC. As ideias expressadas neste artigo são de responsabilidade de seus autores, não representando, necessariamente, a opinião dos editores ou da universidade.

\section{EDITORES}

Mauricio Roberto da Silva, Giovani De Lorenzi Pires, Rogério Santos Pereira.

\section{EDITOR DE SEÇÃO}

Rogério Santos Pereira

\section{REVISÃO DO MANUSCRITO E METADADOS}

João Caetano Prates Rocha; Keli Barreto Santos; Juliana Rosário.

\section{HISTÓRICO}

Recebido em: 26 maio 2021

Aprovado em: 23 novembro 2021 